Hydraulic Engineering Repository

Ein Service der Bundesanstalt für Wasserbau

Heibaum, Michael; Trentmann, Justus

Partial Grouted Riprap for Enhanced Scour Resistance

Verfügbar unter / Available at:

https://hdl.handle.net/20.500.11970/100257

Vorgeschlagene Zitierweise / Suggested citation:

Heibaum, Michael; Trentmann, Justus (2010): Partial Grouted Riprap for Enhanced Scour Resistance. In: Burns, Susan E.; Bhatia, Shobha K.; Avila, Catherine M. C.; Hunt, Beatrice E. (Hg.): Proceedings 5th International Conference on Scour and Erosion (ICSE-5), November 7-10, 2010, San Francisco, USA. Reston, Va.: American Society of Civil Engineers. S. 1-10. 


\title{
Partial Grouted Riprap for Enhanced Scour Resistance
}

\author{
Michael Heibaum ${ }^{1}$ and Justus Trentmann ${ }^{2}$
}

\begin{abstract}
${ }^{1}$ BAW-Federal Waterways Engineering and Research Institute, Department of Geotechnical Engineering, P.O. Box 2102 53, 76187 Karlsruhe, Germany, PH +4972197263820; email: michael.heibaum@baw.de

${ }^{2}$ Gewatech - Grund- und Wasserbau GmbH \& Co KG, Schiefe Güntke 9, 49090 Osnabrück, PH +49 541121 65-20; email: info@gewatech.de
\end{abstract}

\begin{abstract}
Partially grouted armourstones combine the high resistance against currents and waves of large elements and their flexibility to adapt to ground deformations and the option of installing comparably thin layers. With partial grouting smaller and such often cheaper armourstones can be used to form conglomerates with the same resistance as large armourstones. Grouting can be done in fresh water and in saltwater. Segregation and erosion of the grout when poured or dumped or when fresh grout is loaded by currents and waves is avoided by using special chemical additives or by high speed centrifugal mixing (colloidal mortar) - common anti-wash-out mortar is not applicable. Stone diameters of 10 to $40 \mathrm{~cm}$ and a narrow rock size distribution are best for being grouted. To guarantee a successful application of partial grouted armours, a number of tests before, during and after installation have been established for quality assurance.
\end{abstract}

\section{INTRODUCTION}

Scour is a result of the interactions at the boundary of water and soil. In many cases it is considered a hydraulic problem only, looking at it from the water side. So nearly all approaches to assess scour development represent the hydraulic point of view and consider the stability of the top layer, only. But one has also to consider all layers that are influenced by the hydraulic load including the interaction of the surface water and the pore water. On the other hand, sublayers need no consideration if the stability of the top layer is $100 \%$ guaranteed! Such stability can be achieved by grouting the top layer to keep the armour material in place even under high hydraulic actions.

An important parameter for designing a scour protection is the surface geometry of the protected area. Shallow beaches and banks are much less susceptible to scouring than steep banks or structures like breakwaters and dikes with steep slopes. The stability of armour elements decreases with an increase ot the inclination of the surface. Since often surface geometry cannot be modified to 
the desired shape, solutions have to be sought to stabilize the armour without increasing their size to unproportional dimensions, e.g. grouting the top layer.

Partial grouting (Fig.1) is a reliable and well established method to meet the requirements for a long lasting scour protection including sufficient permeability to avoid excess water pressure below the armour. With this method, the stability of the traditional armour made of loose elements is increased to a very large extent. Partial grouting means filling the voids of a riprap layer to $35-50 \%$ with a special mortar, thus creating an armour layer with high resistance, (still) high permeability and sufficient flexibility. Generally partial grouting of armour stones is used if the stability of armourstones is not sufficient due to the magnitude of the hydrodynamic action (waves, turbulent flow) and because of the weight of the armourstones, thickness of the armour layer and slope inclination.

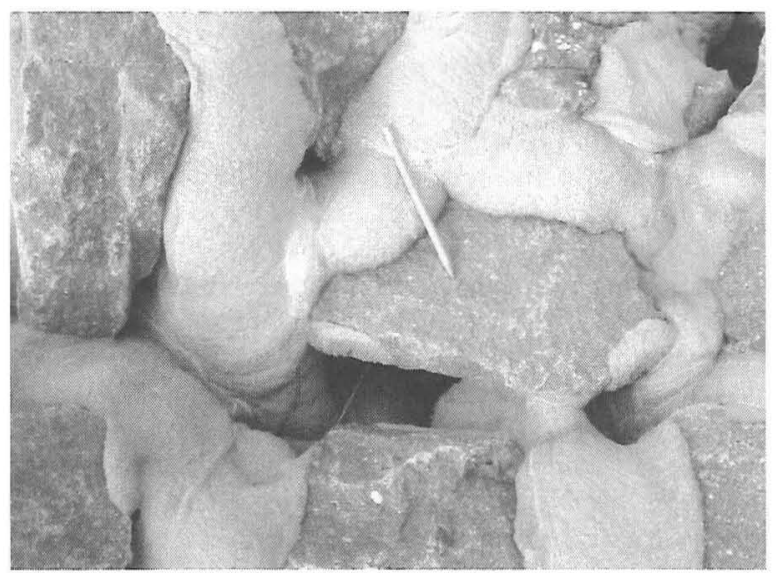

Figure 1. Partially grouted riprap

\section{ARMOUR LAYER}

\section{General}

An armour layer to prevent scouring may be permeable or impermeable. If impermeable systems are used, the development of excess pore water pressure below the layer should be ruled out. Excess pore water pressure or uplift pressure often is one of the reasons for damage of the armour layer or even the whole system. A steady excess pore water pressure (uplift pressure) may be caused by a high groundwater table compared to the level of the surface water. An unsteady excess pore water pressure below the cover layer develops when there is a rapid lowering of the surface water level, for instance due to waves or a ship induced drawdown. But even in the subsoil below permeable cover layers an excess pore water pressure may develop, however to a lesser extent. Since natural water is not an ideal (incompressible) fluid, the pore water pressure will lag the surface water 
pressure change. The length of this time delay depends on the permeability and the saturation of the subsoil.

At the coast, impermeable protection is used in many places. The top layer in most cases is fully grouted riprap, using bituminous or concrete grout. Sometimes a lining of asphaltic concrete, cast asphalt or cement bonded material is installed. Also geosynthetic mattresses with concrete fill are used. To avoid the development of excess water pressure, often a permeable cover layer is recommended for scour countermeasures. At first sight, a permeable cover layer seems to ask for more effort and costs compared to an impermeable one. A filter is always needed and the placement of the top layer material has to be done much more accurately, but in the end such a system is more successful in most cases.

\section{Flexibility (serviceability)}

Besides the problem of excess water pressure below the lining, a second problem occurs with impervious armour layers, namely suberosion of the soil from below the lining. Only in ponds and narrow rivers can the lining be placed from one side of the water to the other. So the toe of the armour layer of coastal protection and protection of wider rivers is a critical point. The soil may be washed out from under the layer, initiating regressive erosion and resulting in large voids. This is even intensified by the fact that all the impervious armour layers are rather rigid - even the bituminous systems. Due to these boundary conditions, erosion can occur over a long time without being detected, since the strength of the armour is high enough to bridge the voids, but finally a large collapse occurs (Fig. 2).

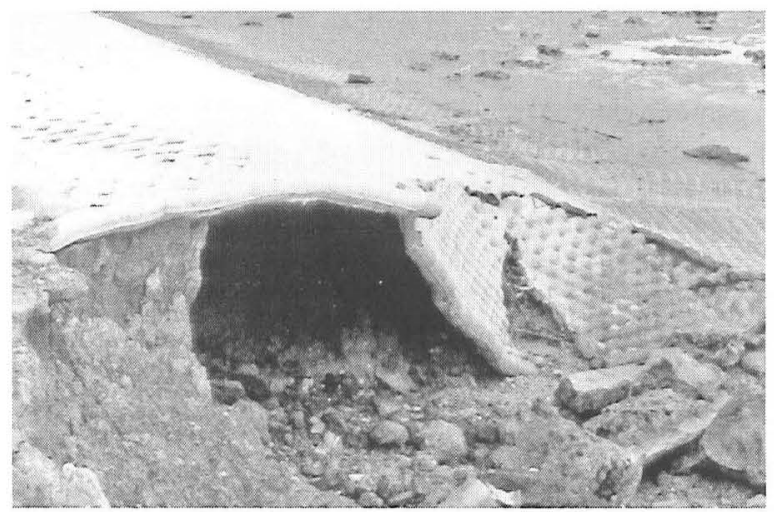

Figure 2. Failed concrete mattress lining

Scouring is a dynamic geomorphic process that can be stopped completely only with major effort. Scouring at the borders of scour protection is inevitable but it can be accepted to a certain extent, if the protection system is chosen appropriately, hence resulting in a major requirement: a good scour protection system has to be flexible. The demand for flexibility holds for all elements of scour repair and 
prevention work, i.e. fill, filter and armour. The best measure possible will be implemented when all layers adapt to the geometry given and are able to follow a changing geometry due to hydrodynamic processes. Secondary scouring at the edges of a scour protection layer is nearly inevitable, since the transition from an artificial to a natural bed always causes local erosion. So only a flexible protection layer guarantees the adaptation to the newly developing geometry until an equilibrium is reached. (Another option would be to bury the toe to a sufficient, i.e. rather great, depth.)

\section{Armour elements}

To meet the above mentioned requirements of permeability and flexibility, the armour for a scour countermeasure is built from single elements that may be placed randomly or regularly, mutually connected or loose.

Armourstones or riprap is maybe the most often used material for protection systems to stop or to reduce scouring or to rehabilitate existing scour holes. Solutions at reasonable costs can be attained if this material is sufficiently available. Sometimes riprap is considered a temporary countermeasure only, an opinion which may originate from the use of stones that are too small or from armour layers without a filter beneath.

Concrete elements are used when natural material is not available to the necessary extent. The production costs are much higher but their use is justified if the transportation distance of rock is too large. In certain cases it may be beneficial to produce the elements on-site. There is a large variety of concrete elements that are used as an armour layer. They will not be listed here in detail, but there are three groups to be mentioned: Elements of many different shapes that are used like riprap, blocks that are placed regularly ("paved") and elements that are mutually connected.

\section{Stability of armour elements}

The resistance of all single elements against hydrodynamic forces increases with the weight of the element. But increasing the weight, which is usually linked with an increasing diameter, means increasing the layer thickness, too. And since the voids between larger elements also become larger, the elements of the layer below (filter or cushion layer) have to be larger to ensure their not being eroded through the cover layer. Maybe even an additional layer is necessary. But an increasing layer thickness may be incompatible with the geometry requirements.

To limit the thickness of the armour layer but to provide a comparable resistance against the erosive forces of currents and waves, cover layers with mutually connected elements can be fabricated. The general idea is to use smaller and often cheaper elements, but simultaneously to gain high resistance against the hydraulic load by connecting them to larger elements, to "mattresses" or to continuous layers. Examples of permeable continuous layers are open stone asphalt, mutually interlocking or cable connected concrete elements, stone mattresses etc.

A paved cover layer (natural stones or concrete blocks) also shows an increased resistance against hydraulic loads while remaining limited in thickness. 
But the high resistance is lost if only one element is missing and the permeability is limited since one element is placed very close to the next.

The use of gabions is a well known method to achieve large elements with only small voids. Gabions are made of riprap or even smaller stones filled in a wire mesh basket. They are very versatile elements concerning the shape of the single element as well as the shape of the whole cover layer. Gabions may be prefabricated or - in the dry only - filled in place.

Stone mattresses are similar to gabions and manufactured like these. They are usually thinner than gabions, but cover a larger area. If placed in the dry, they can be connected to each other thus creating a continuous armour layer. Mattresses are prefabricated when they are placed in the wet, but up to a few square metres only due to the weight.

Cable connected systems are similar to stone mattresses, and like mattresses, their size is limited when placed in the wet. In the dry they can be assembled continuously, depending on the system.

Open stone asphalt is a very well known continuous cover layer in coastal protection, but can be placed only in the dry. In the wet prefabricated mattresses of open stone asphalt are used.

Continuous layers also may be created by so called geosynthetic mattresses filled with concrete or mortar. They can be placed continuously with the fabric sewn together as needed and then filling the mattress. Mattresses of uniform thickness would be inflexible and impermeable. To achieve a certain flexibility and permeability, mattresses consisting of columns and rows of "pillows" are used - like mutually connected bags. The seams between the concrete filled pillows provide the necessary permeability of the layer and the desired flexibility for good adjustment to any deformation of the subsoil.

All cable connected systems, gabions and stone mattresses are endangered by corrosion and abrasion of the cables or the wire mesh, so the long term stability of both steel and polymer wires is limited. Abrasion is due to sediment transport or due to the relative movement of wire or cable and armour element. Gabions and stone mattresses cannot be filled so tightly that the stones do not agitate at all under the hydraulic load.

Partial grouting allows for both, creating larger elements or a layer of mutually connected elements of minor thickness. Conglomerate-like larger elements (Fig. 3) are similar to gabions. But also a continuous layer may be created by spreading the grout in an appropriate manner.

Grouting has proved its long term stability and its ability to keep the costs low. Laboratory tests at the Braunschweig University, Germany, proved stability up to a flow velocity of $8 \mathrm{~m} / \mathrm{s}$ (test report unpublished). Since the riprap is dumped or placed as needed and only then the layer is grouted, any shape of the cover layer may be obtained. Thus a close contact to structural elements like piers, piles or walls can be achieved. 


\section{GROUTING}

\section{General}

With full grouting the voids between the armourstones are filled with grouting material completely. With partial grouting only parts of the voids between the armourstones are filled with grout. Grouting materials are liquid during installation and solidify after a certain hardening period. This period depends on the type of material. Cement bonded grouting materials are made of cement, aggregates and water as well as optional additives. Bituminous grouting materials are made of bitumen, sand and filler (grain size $<0.09 \mathrm{~mm}$ ). The only bitumen bonded grouting material considered applicable for impermeable grouting is asphaltic mastic. Grouting can be done in fresh water and in saltwater.

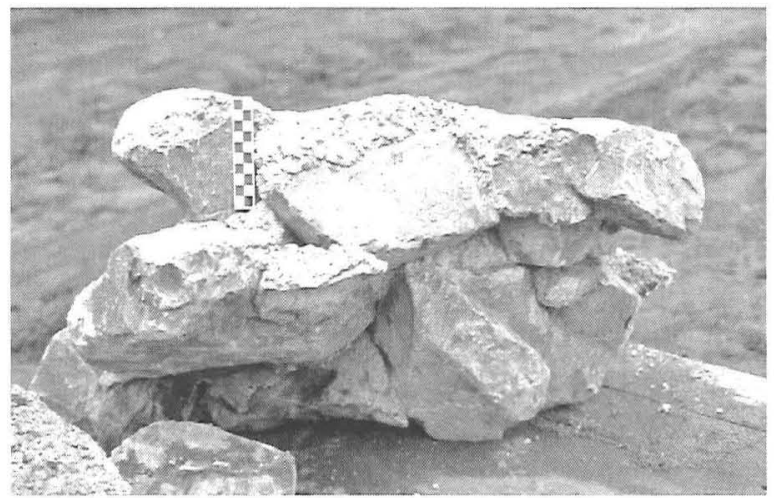

Figure 3. Conglomerate of grouted riprap

Partial grouting is done line by line or spot by spot, the latter resulting in conglomerate-like elements while the former results in a continuous layer. With the correct amount and the correct distribution of the grout the armour layer still remains flexible to follow the ground deformation.

To stabilize the position of the armourstones, generally it is sufficient to fix the stones on the surface of the armour layer. In case of high wave loads or strong turbulent flow (e.g. propeller wash, flow over weirs) an armour layer must be grouted in such a manner that every stone is fixed against lift forces. Consequently, the grouting material must be distributed over the entire cross section of the armour layer. Usually less than $50 \%$ of the voids are filled with grout. A permeability of more than $1 \times 10^{-3} \mathrm{~m} / \mathrm{s}$ should be guaranteed.

With increasing hydrodynamic effects on the armour layer the grouting material quantities as well as the grouting depth must increase. To achieve a sufficient bonding effect as well as simultaneously a sufficient water permeability of the armour layer, great care has to be taken that the distribution of grouting material in the armour layer meets the requirements.

For stability reasons the water permeability of the armour layer on permeable ground must be larger than the permeability of the underlying filter. Based on 
experience, this criterion is fulfilled in most cases if the remaining void ratio is not less then $10 \%$ in any layer or volume.

\section{Armourstone requirements}

The requirements for armourstones used in revetments are laid down in the European Standard EN 13383-1 which specifies various standard size classes. Small armourstones are defined by the sieve perforation size, D, (size of the square perforations) and are referred to as class $\mathrm{CP}_{\mathrm{x} / \mathrm{y}}$ (Coarse Particle, $\mathrm{x}$ being the lower class boundary [mm] and y the upper class boundary $[\mathrm{mm}]$ ). The larger classes are defined by the weight, $\mathrm{G}$, of the stones as light gradings $\mathrm{LM}_{\mathrm{x} / \mathrm{y}}$ (Light Mass, $x=$ lower class boundary $[\mathrm{kg}], y=$ upper class boundary [kg]) or heavy gradings $\mathrm{HM}_{\mathrm{x} / \mathrm{y}}$ (Heavy Mass).

The size class $\mathrm{CP}_{90 / 250}$ with a mean diameter of $\mathrm{D}_{50}=150 \mathrm{~mm}$ is recommended for the construction of partially grouted cover layers. The proportion of fines in the size class must be limited by specifying $90 \mathrm{~mm}$ as the minimum value of $\mathrm{D}_{5}$ in order to ensure a sufficiently large void size. Stones of class $\mathrm{LMB}_{5 / 40}$ (mean weight $\mathrm{G}_{50}=14 \mathrm{~kg}$ ) may also be used. Generally, the void size distribution should be even, which is achieved by narrowly graded riprap.

Qualified placing of the armourstones is essential for a successful installation of partial grouted armour layers. Placing under water usually is done mechanically by special equipment (dumping pontoons). No additional grading or pushing down by an excavator shovel or else should be done.

\section{Grout requirements}

Cement bonded grouting materials are recommended for partial grouting. Cement grouting "glues" one stone to the next, while asphalt grouting only forms a "clamp" to hold the single stone in place. Therefore bituminous grouting materials (asphalt) are not further dealt with.

There are a number of requirements for grouting material to be met for successful application:

- The basic materials need to match a building material standard or to have the valid registration mark of an approved testing laboratory.

- The basic materials need to pass a quality control.

- The grouting material must be harmless towards environment. (Cement bonded grouting materials are harmless towards environment if approved constituent materials are used.)

- The grouting material must have a long-term resistance.

The grouting material in fresh condition must be in such a liquid stage that the voids of a riprap layer are filled in the requested manner. The flow characteristic of cement bonded grouting material is different when being installed under water or in the dry. Consequently testing results of installation in the dry do not apply to installation under water.

Fresh grout needs high resistance to erosion, i.e. the grout must not segregate when poured through water or dumped. This holds always when installed under water and for the installation in the dry, if currents and wave actions are possible on the freshly grouted layer (e.g. tide region). Standard cement bonded 
grouting materials only have a high resistance to erosion if they are combined with suitable chemical additives. A high resistance to erosion is also established through the preparation of a cement bonded grouting material in a colloidal mill with high velocity shear action $(2200-2500 \mathrm{U} / \mathrm{min})$. Common anti-wash-out mortar is not applicable.

High resistance to frost is required if the grouted layer is installed in a zone of fluctuating water level up to $1 \mathrm{~m}$ under the lowest local water level and in the high water level zone.

The consistency of the grout should be such that the amount of fill is never filling the voids too much and decreasing from top to bottom. If the consistency is too low, the grout will flow through the armourstones and clog the filter. If the consistency is too high, only the top voids will be filled, leading to an insufficient permeability. The system and the grout chosen have to prove their ability by tests, since the grout behaves different in the dry and under water. Usually test boxes with a base of at least $3 \mathrm{~m}^{2}$ are installed under water, filled with armour layer material and lifted again after being grouted to check the result (Fig. 4). The grout distribution should be as desired and the bond strength of a single stone should be above $2 \mathrm{kN}$ per stone.

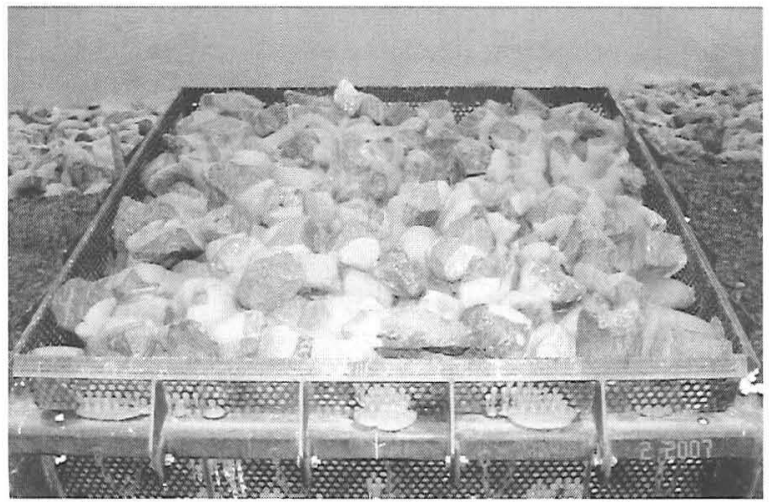

Figure 4. Test box to check grout distribution and/or permeability

\section{Installation}

Installation should be done only by a qualified contractor and skilled and well trained workers. Placement of grout below the water table needs either divers (for small areas and narrow spaces) or special machines. Only to a water depth of $1 \mathrm{~m}$ it can be done by hand from above the water table. The tremie method is not applicable for partial grouting.

The armourstones must have a clean surface in order to achieve the desired results of bond strength with the grouting material. Consequently, the grouting work must be done immediately after installation of the armourstones. If sediments are left behind from floods or construction procedures the dirty ar- 
mourstones must be cleaned and the voids must be free of any debris. If there is doubt concerning the quality of the cleanliness, the bond strength must be tested.

Cement bonded materials installed in the dry must follow the guidelines for the curing of concrete and therefore must be kept moist especially when exposed to high temperature and sunlight.

Frozen armourstones are unfavourable for grouting.

\section{TESTS}

\section{Resistance to erosion}

In order to test the resistance to erosion according to the "washing out method", the grouting material is placed in screened basket, which is then dropped three times through a water tank of $1 \mathrm{~m}$ height (Fig. 5).

The test procedure is as follows: $2000 \mathrm{~g}$ of the grouting material is filled into a screened basket (mesh width of the sieve $3 \mathrm{~mm}$ ) and is then compressed by tamping it lightly. The screened basket is then dropped through the $1 \mathrm{~m}$ high water column in the test cylinder in free fall. Afterwards the basket is raised. This procedure is repeated two times. Then the loss of mass of the grouting material is determined, with a permissible loss of mass $<6 \%$.

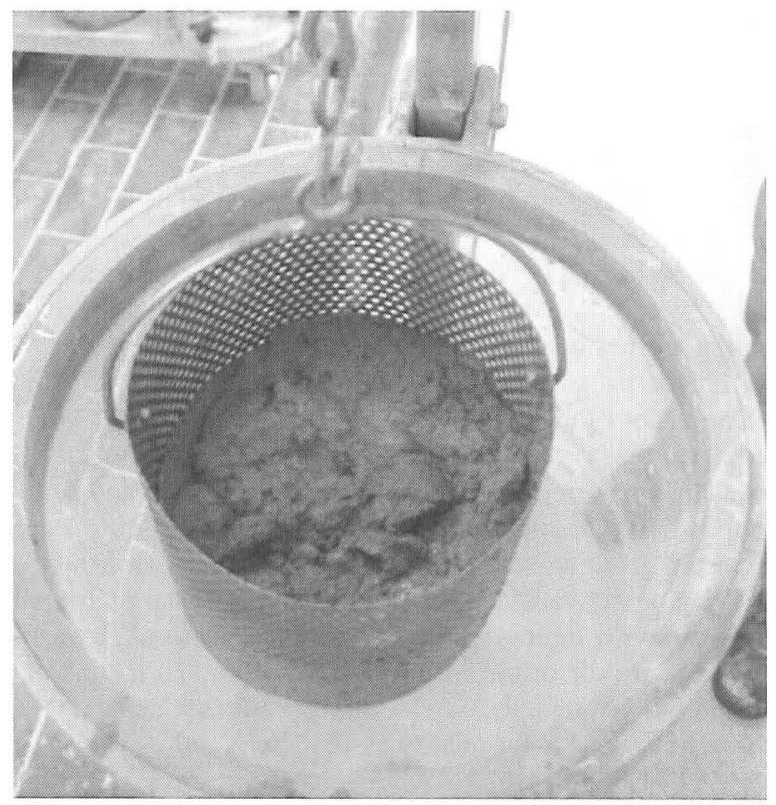

Figure 5. Test apparatus for the washing out method 


\section{Grouting material quantities and distribution}

A test cylinder or box is filled with armourstones to the required layer thickness (Fig. 4). First the weight of the empty test cylinder is determined, then the total weight followed by determining stepwise the weight differences of the test cylinder when dipping it into water in $5 \mathrm{~cm}$ steps. The void ratio of the rock fill for different steps is calculated from these weight differences. The armourstones in the test box are grouted according to the construction method. After the solidification of the grout, the immersion weighing of the test box is repeated using the same steps as before. Based on the comparison of the weight of the respective immersion depths the void volume filled with grout or the remaining void ratio is calculated from the known dry density of the grouting material.

\section{Water permeability}

The testing of the water permeability ( $k$-value) of partially grouted armour layer is performed on at least 2 test samples. This test is done with a special test apparatus similar to the one used for the determination of the grout distribution according to the principle of falling hydraulic head.

\section{Bond strength}

In order to test the bond strength of grouted armour layers at least 5 nonneighbouring stones of the top rock layer must be supplied with an anchor bolt. After solidification the tensile force is measured when pulling the stone from the grouted layer.

\section{CONCLUSION}

A protection system suitable as scour countermeasure should be permeable to avoid excess water pressure below the armour layer. Furthermore it has to meet the following requirements:

- being flexible so as to be able to follow soil deformations and further scouring at the edges,

- incorporating a filter to avoid winnowing or contact erosion,

- having sufficient resistance against the hydraulic loads.

There are a lot of systems available for armour layers. Among them partially grouted riprap has proved to perform extremely well, since it combines the high resistance against currents and waves of large elements and their flexibility to adapt to ground deformations with the possibility of building comparably thin layers. With partial grouting smaller and such often cheaper armourstones can be used to form conglomerates with the same resistance as large armourstones. And partial grouting allows a tight connection to other structural elements since often these contact zones are the origin of progressive scour. To guarantee a successful application of partial grouted armours, a number of tests before, during and after installation have to be passed for quality assurance.

\section{REFERENCE}

EN 13383-1: Armourstone - Part 1: Specification (2002-05) 